\title{
Adaptación de competencias al marco de la Economía Digital en el grado de Información y Documentación: Universidad de Murcia
}

\section{Digital Economy framework, skills adaptation to the degree of Information and Documentation: University of Murcia}

\author{
María García-González \\ ${ }^{1}$ Profesora Asociada en el Departamento de Información y Documentación. \\ Facultad de Comunicación y Documentación (Campus Espinardo). Universidad \\ de Murcia, España. Correo electrónico: mariasegunda.garcia@um.es. ORCID: \\ 0000-0002-1640-9623
}

\section{Resumen}

Se pretende abrir un debate a partir del estado de la situación en el que se encuentra el grado de Información y Documentación de la Universidad de Murcia. Se procede a la ejecución de una serie de fases que pasan desde el análisis y evaluación actual de competencias específicas del grado, así como de su aproximación a nuevas competencias demandadas en el nuevo mercado de la economía digital ${ }^{2}$. Para ello, se someten a estudio las guías docentes, se contrastan resultados con el Libro Blanco del Título de grado en Información y Documentación (ANECA, 2004) y se adaptan algunas competencias específicas a las propuestas por el Libro Blanco para el Diseño de Titulaciones Universitarias en el Marco de la Economía Digital (ANECA, 2015). Esta actuación permite ofrecer una visión en tres dimensiones: la existencia del solapamiento de contenidos en las asignaturas del grado; la necesidad de afrontar un nuevo cambio en el plan de estudios sin perder el sello de identidad y finalmente, asumir nuevas competencias específicas para satisfacer las demandas del nuevo mercado de la Economía Digital.

Palabras claves: Economía digital; competencia digital; mercado laboral; grado en información y documentación; educación superior.

\footnotetext{
${ }^{2}$ Competencia Digital: [...] 1. es una combinación de conocimientos, habilidades destrezas y actitudes, para acceder, analizar, evaluar, reflexionar críticamente, crear y actuar en cuatro diferentes áreas o alfabetizaciones: tecnológica, informacional, multimedia y comunicativa. Una competencia compleja, formada por una alfabetización múltiple. 2. Ser competente digital implica ser capaz de combinar estas cuatro alfabetizaciones de manera simultánea, para dar respuesta a problemas o situaciones a cualquier nivel de complejidad: no para solo conocer y comprender, sino también para aplicar, analizar, sintetizar y evaluar [...] (Esteve y Gisbert, 2011).
} 


\begin{abstract}
The intention is to launch a discussion about the current situation concerning degree in Information and Documentation at University of Murcia, a series of phases are made to analyze and evaluated the current specifics skills of the degree on these days, furthermore, to see their approach to the new skills demanded in the new market of the Digital Economy, for that purpose, the teaching guides are studied, results are contrasted with «White Paper on the degree title in Information and Documentation» (ANECA, 2004) and some of specific skills are adapted with «White Paper for the Design of University Degrees in the Framework of the Digital Economy» (ANECA, 2015). This situation provides a vision in three dimensions: Overlap of contents between the subjects of the degree; a new change is needed in the curriculum and it is also necessary to define the new specifics skills to cover the new market demands of the Digital Economy. Keywords: Digital economy; skill digital; professional profile; degree in information and documentation; higher education.
\end{abstract}

Fecha de recibido: 30/09/2019

Fecha de aceptado: 20/10/2019

\title{
1. Introducción
}

Con la aparición del Espacio Europeo de Educación Superior, en el año 2007, los anteriores planes de estudios se extinguieron o transformaron (en 2015 dejaron de existir en todas las universidades españolas). Los estudios de grado del Plan Bolonia (grado de Información y Documentación) que se ofrecen actualmente en catorce centros, fueron una respuesta tanto a la disminución de la demanda como a las condiciones del mercado de trabajo: una disminución del número de ofertas públicas de empleo y un aumento equivalente en el sector privado (Montes López, 1995; ANECA, 2004; Tejada; Moreiro, 2003; Abadal; Borrego; Serra, 2012). El objetivo de los nuevos planes de estudios era ofrecer una educación que permitiera una mayor expansión profesional y una especialización más ajustada a la realidad (Morales, 2012).

En España, las oportunidades que ofrecen las TIC han cobrado cierta fortaleza en las actuaciones públicas, como lo indica la Agenda Digital para España y la ramificación de la gran coalición en España (Pledge of Spanish Grand Coalition for a Digital Jobs) puesta en marcha en 2013, que persigue mejorar las competencias digitales estableciendo una serie de prioridades en materia de formación, certificación, aprendizaje y enseñanza innovadora, movilidad y promoción para atraer a los jóvenes hacia el sector productivo (Álvarez et al., 2019).

La Oficina Regional de Educación para América Latina y el Caribe (2013) remarca que la formación en competencias digitales es cada vez más importante en el ámbito educativo, como una necesidad para la inclusión en la sociedad del conocimiento. Bajo su criterio, tal y como mantienen otros autores (Moeller et al., 2011), las TIC no son sólo un potente recurso para el aprendizaje, son herramientas cada vez más relevantes para la vida. En relación con la empleabilidad de los trabajadores, las TIC permiten propiciar la evolución de 
modelos docentes tradicionales a modelos más flexibles, abiertos y participativos, tales como Comunidades Mediadas por Ordenador (CMO) y los Entornos Personales de Aprendizaje conocidos como PLE (Personal Learning Environment) que faciliten la adquisición de competencias digitales necesarias para la incorporación al mercado laboral (Fundación Telefónica, 2012).

Otras aportaciones se alinean con el desarrollo de competencias clave (Rychen y Salganik, 2008), el fomento de la capacidad reflexiva y autónoma del alumno/a (Boisvert, 2004), los retos que planea para la educación la aparición de la generación net (Hargittai, 2010), enseñar a nativos digitales (Prensky, 2011), la formación empresarial en ambientes virtuales (Reinoso, 2012), el papel de la universidad digital en la captación de talento para la integración del conocimiento a la sociedad (Freire y Schuch, 2010), el mapa de competencias digitales (AlaMutka, 2011), el aprendizaje invisible (Cobo y Moravec, 2011), y los nuevos paradigmas de aprendizaje y nuevas tecnologías (Esteve y Gisbert, 2011). Entre ellos, el entrenamiento del pensamiento creativo para el emprendimiento (Byrge y Hansen, 2013; Elliot y Nakata, 2013). La OECD, por su parte, las define como algo más que conocimientos y habilidades, afirma que deben incluir las capacidades para satisfacer demandas complejas a través de la utilización de los recursos psicosociales (incluyendo habilidades y actitudes) en un contexto particular (OECD, 2005:4).

La situación planteada por la Agenda Digital para España (ADpE), aprobada por el Consejo de Ministros en febrero de 2013, recoge como objetivo específico el desarrollo de la Economía Digital para el crecimiento, la competitividad y la internacionalización de la empresa española. En el marco de la $\mathrm{ADpE}$ se ha elaborado el «Plan de Impulso de la Economía Digital y los Contenidos Digitales», dentro del cual, se incluye la actuación de «formación para la excelencia» que responde a la necesidad de promover la calidad en la formación para el sector de la Economía Digital (ADpE 3, 2015). La motivación de la puesta en marcha de esta iniciativa se basa en el hecho de que, en la actualidad, el sector de la Economía Digital demanda perfiles profesionales cada vez más especializados en este ámbito y, por ello, se está produciendo una transformación de la oferta formativa apostando las universidades por este tipo de titulaciones. Es este un sector nuevo y dinámico en el que hay pocas referencias y por lo tanto existen dificultades para su diseño y puesta en marcha. Tal es así que en «El Plan de Inclusión Digital y Empleabilidad» de la Agenda Digital para España (20132015), se planteó como objetivo potenciar una mejora de la oferta universitaria destinada a la formación de profesionales TIC a través de su adaptación a las necesidades del mercado, contemplando los nuevos perfiles profesionales en el ámbito de las TIC y el incremento de la eficiencia del sistema (ADpE 7, 2015).

Del análisis anterior, se concluyó que resultaba necesario trabajar conjuntamente en la elaboración de un Libro Blanco para el diseño de titulaciones universitarias en el ámbito de la Economía Digital, que tuviera en cuenta la oferta para formar profesionales en este sector y al mismo tiempo, permitiera cubrir las necesidades de profesionales identificadas. Tal es así, que se considera que los estudios de grado en Información y Documentación podrían vincularse al sector de la Economía Digital adscribiéndose en el Libro Blanco al ámbito de estrategia y gestión de negocio digital (ANECA, 2015), pero la actual oferta formativa de grado no está vinculada con el sector de la Economía Digital, por tanto, no puede 
cubrir las actuales necesidades sociales y del mercado laboral. Esta evidencia, en particular, puede verse corroborada en los datos proporcionados tanto en la última reunión celebrada el 25 de octubre de 2018 por parte de la comisión del grado en Información y Documentación de la Universidad de Murcia, en el último informe de perspectivas profesionales de las personas tituladas de la UMU (ofrecidos por el Centro de Orientación e Información de Empleo (COIE)) de fecha 2016, así como en la memoria verificada por la ANECA del título de grado en Información y documentación (FCD, 2010) en los que podemos ver datos negativos: en el grado de Información y Documentación se viene observando una alta tasa de abandono de alumnos/as de primer curso. Según los últimos datos recogidos en la tabla de resultados académicos para el curso 2017/2018, en torno a un 57,81\% y su correspondiente traslado de expediente a otras titulaciones. En cuanto a los datos sobre empleabilidad el $55,6 \%$ de alumnos/as de la Facultad de Comunicación y Documentación han tenido alguna actividad laboral durante la carrera, y el 53,8\% de alumnos/as han tenido trabajos esporádicos en cuanto a las actividades que se pueden desarrollar en el contexto universitario y que favorecen la empleabilidad de los/as estudiantes. Las actividades más comunes de las personas recién tituladas son las prácticas extracurriculares con un 68,5\%. En cuanto a la situación laboral de alumnos/as titulados, en el momento de realizar la encuesta (2016) se encontró que el 64,4\% de alumnos/as de la Facultad de Comunicación y Documentación no tenían un contrato laboral (COIE, 2016).

Además de los datos ofrecidos, analizando los resultados del «Estudio de Perfiles Profesionales más demandados en el ámbito de los Contenidos Digitales en España (2012-2017)», promovido por la Fundación de Tecnologías de la Información (FTI) en colaboración con la Asociación de Empresas de Electrónica, Tecnologías de la Información, Telecomunicaciones y Contenidos Digitales de España (AMETIC) (PAFET, 2012-2017), se encuentra una propuesta que abarca todos los ámbitos que afectan a la oferta y demanda de perfiles profesionales en el entorno de los contenidos digitales, vinculando la formación del grado en Información y Documentación con las áreas propuestas en el Libro Blanco (ANECA, 2015): tecnología de la innovación; arte, diseño visual y creatividad; estrategia y gestión de negocio, asignándoles los siguientes perfiles:

1. Gestor de publicaciones digitales, relacionado con los siguientes perfiles: IT, Producción y Editor;

2. Content Curator, relacionado con los siguientes perfiles: Community Manager, Gestor o responsable de comunidades, Especialista en Marketing Online, Content Editor Communications, Global Marketing Strategy Manager y Digital Strategy Manager;

3. Consultor Digital, relacionado con el siguiente perfil: Consultor en eHealth;

4. Arquitecto de contenidos: Especialista UX.

Esta situación muestra dos perspectivas: por un lado, estudios que ofrecen cuáles son los nuevos perfiles profesionales más demandados en el mercado de la Economía Digital y por otro lado, la capacidad de desarrollar estudios que vinculen la formación de los nuevos perfiles profesionales con la posibilidad de que sean asumidos por los estudios de grado en Información y Documentación. 
Este nuevo contexto supone una transformación en el grado de Información y Documentación de la Universidad de Murcia. Implica el análisis de las distintas variables presentadas en el nuevo escenario, donde se debe evaluar la posición en la que se encuentra el grado para adoptar nuevas medidas de cambio, y de nuevo, fijar lo que corresponde por exclusividad.

\section{Objetivos}

Analizar y evaluar las competencias específicas que actualmente tiene el grado de Información y Documentación de la Universidad de Murcia. Éste se rige por aquellas competencias reflejadas en el Libro Blanco Título de Grado en Información y Documentación (ANECA, 2004).

Comparar el grado de implantación de las competencias específicas del grado de Información y Documentación, respecto de las señaladas en el Libro Blanco Título de Grado en Información y Documentación (ANECA, 2004).

Analizar y evaluar las nuevas competencias reflejadas en el Libro Blanco para el Diseño de Titulaciones Universitarias en el Marco de la Economía Digital (ANECA, 2015) y estudiar la propuesta presentada en el «Estudio de Perfiles Profesionales más demandados en el ámbito de los Contenidos Digitales en España (2012-2017)», en el que cabe la posibilidad de vincular la formación del grado en Información y Documentación a cuatro perfiles profesionales de las áreas que se proponen.

Comparar en qué medida las actuales competencias específicas del grado de Información y Documentación, señaladas en el Libro Blanco Título de Grado en Información y Documentación (ANECA, 2004), pueden adaptarse a las nuevas competencias reflejadas en el Libro Blanco para el Diseño de Titulaciones Universitarias en el Marco de la Economía Digital (ANECA, 2015) y al «Estudio de Perfiles Profesionales más demandados en el ámbito de los Contenidos Digitales en España (2012-2017)».

Identificar las competencias no desarrolladas o desarrolladas de forma deficiente en el número total de asignaturas, para detectar posibles lagunas en la nueva oferta formativa.

Ofrecer aproximaciones entre el antiguo marco desarrollado de competencias y el nuevo escenario, que den lugar al debate y consenso entre profesionales expertos del área.

\section{Metodología}

Para realizar el proceso de análisis de competencias se procede, secuencialmente, de la siguiente manera ${ }^{3}$ :

\footnotetext{
${ }^{3}$ Para realizar el proceso de evaluación de competencias, se ha tomado de referencia la metodología aplicada en el trabajo realizado por Agustín y Salvador en el año 2016 para el análisis y evaluación de las competencias del grado en Información y Documentación de la Universidad de Zaragoza.
} 
a) En primer lugar, se trabaja con las guías docentes de las asignaturas de formación básica, obligatoria y optativa del curso académico 2018/2019 del grado en Información y Documentación, disponibles en la página web de la Universidad de Murcia. No se han incluido el trabajo fin de grado ni el prácticum (UMU, 2019). El Plan de Estudios estableció una serie de competencias generales y específicas para la definición de todas las competencias diferentes (CGUxx, CGTxx, CETxx), así como su distribución en las distintas materias. Para su definición se tuvo en cuenta el Libro Blanco del Título de Grado en Información y Documentación (ANECA, 2004), el documento de trabajo European Curriculum Reflections on Library and Information Science (RSLIS, 2005) y las líneas de orientación general marcadas por los Honours Degree Benchmark Statement de la European Quality Assurance Agency for Higher Education y por el Bologna Handbook. (QAA, 2018).

b) En segundo lugar, se comprueba el número total de la presencia de las competencias específicas en cada una de las asignaturas, analizando una por una las guías docentes de las asignaturas pertenecientes a Formación Básica, Obligatoria y Optativa.

c) Para comparar el grado de implantación de las competencias específicas del grado de Información y Documentación, respecto de las señaladas en el Libro Blanco Título de Grado en Información y Documentación, se mide el grado de adecuación, en número de créditos, de las asignaturas troncales del grado respecto de las recomendaciones dadas en los contenidos comunes obligatorios (troncales) del Libro Blanco (ANECA, 2004).

d) A continuación, se procesa la información en un programa estadístico para obtener los resultados porcentuales de la presencia de competencias en cada una de las asignaturas, quedando reflejados en las tablas diseñadas a tal efecto, ver tablas 2 y 3 (SPSS statistics 24).

e) Finalmente, se extraen las competencias vinculadas del Libro Blanco para el Diseño de Titulaciones Universitarias en el Marco de la Economía Digital, desarrollando unos criterios de proximidad con las competencias específicas actuales del grado en Información y Documentación (UMU) y su posible derivación a esas nuevas competencias establecidas en el Libro Blanco (ANECA, 2015).

\section{Desarrollo}

\section{Plan de estudios del grado en Información y Documentación en la Universidad de Murcia.}

El número total de créditos que componen el grado es de 240 , distribuidos de manera equitativa en 4 cursos tras el modifica propuesto a partir de octubre de $2018^{4}$. El primer y segundo curso están constituidos por asignaturas de formación básica y obligatoria, quedando de la siguiente manera (UMU, 2019):

\footnotetext{
${ }^{4}$ La primera actuación de cambio en el grado en Información y Documentación de la Universidad de Murcia, supone una modificación puntual en los dos primeros cursos del grado, siendo efectiva para el curso académico 2019/2020 sin modificación de créditos ya
} 
Tabla 1: Distribución de créditos del grado en Información y Documentación (UMU)

\begin{tabular}{|c|c|c|c|c|}
\hline Cursos/ Tipo asignatura & Formación Básica & Obligatorias & Optativas & Otros \\
\hline Primer curso & 6 asg. de 6 créditos (36) & $\begin{array}{l}2 \text { asg. de } 6 \text { créditos (12) } \\
1 \text { asg. de } 12 \text { créditos (12) }\end{array}$ & & \\
\hline Segundo curso & 4 asg. de 6 créditos (24) & $\begin{array}{l}2 \text { asg. de } 6 \text { créditos (12) } \\
2 \text { asg. de } 12 \text { créditos (24) }\end{array}$ & & \\
\hline Tercer curso & & $\begin{array}{l}4 \text { asg. de } 12 \text { créditos (48) } \\
2 \text { asg. de } 6 \text { créditos (12) }\end{array}$ & & \\
\hline Cuarto curso & & $\begin{array}{l}1 \text { asg. de } 12 \text { créditos (12) } \\
2 \text { asg. de } 6 \text { créditos (12) }\end{array}$ & 6 asg. de 6 créditos (36) & $\begin{array}{l}9 \text { créditos prácticas } \\
9 \text { TFM }\end{array}$ \\
\hline
\end{tabular}

El número total de asignaturas analizadas han sido 32, las asignaturas con mayor número de competencias son:

- 2536 Planificación, Gestión y Evaluación de Unidades de Información. Primer curso, obligatoria, de 12 créditos y anual.

- 2556 Gestión de proyectos culturales en contextos bibliotecarios. Cuarto curso, 6 créditos, optativa, de 6 créditos y cuatrimestral.

Ambas tienen asignadas 14 competencias de 23, en torno a un $60,8 \%$ del total.

\section{Análisis de las competencias en cada una de las asignaturas del grado en Información y Documentación.}

Tabla 2: Aparición de competencias en asignaturas del grado (Totales, FB, Obl. Optati.)

\begin{tabular}{|c|c|c|c|c|c|}
\hline Competencias específicas/ Asignaturas & Totales & FB & Obl. & Optati. & Total. \% \\
\hline CET1. Interacción con los productores, los usuarios y los clientes de la información. & 18 & 7 & 7 & 4 & $56 \%$ \\
\hline CET10. Elaboración y difusión de la información. & 18 & 6 & 7 & 5 & $56 \%$ \\
\hline CET4. Identificación, autentificación y evaluación de fuentes y recursos de información. & 16 & 4 & 8 & 4 & $51 \%$ \\
\hline CET8. Organización y almacenamiento de la información. & 15 & 6 & 6 & 3 & $46,8 \%$ \\
\hline CET9. Búsqueda y recuperación de la información. & 13 & 4 & 8 & 1 & $40,6 \%$ \\
\hline CET5. Gestión de colecciones y fondos. & 12 & 4 & 7 & 1 & $37,5 \%$ \\
\hline CET20. Técnicas de planificación y gestión de proyectos. & 12 & 4 & 3 & 5 & $37,5 \%$ \\
\hline CET2. Conocimiento del entorno profesional de la información y la documentación. & 11 & 8 & 2 & 1 & $34,4 \%$ \\
\hline CET7. Análisis y representación de la información. & 11 & 3 & 5 & 3 & $34,4 \%$ \\
\hline CET11. Tecnologías de la información: informática. & 11 & 0 & 8 & 3 & $34,4 \%$ \\
\hline CET21. Técnicas de diagnóstico y evaluación. & 11 & 1 & 8 & 2 & $34,4 \%$ \\
\hline CET23. Técnicas de formación. & 9 & 2 & 3 & 4 & $28,12 \%$ \\
\hline CET13. Técnicas de producción y edición. & 8 & 1 & 3 & 3 & $25 \%$ \\
\hline CET3. Conocimiento del marco jurídico y administrativo nacional e internacional de la GI. & 5 & 3 & 2 & 0 & $15,62 \%$ \\
\hline CET19. Técnicas de instalación, acondicionamiento y equipamiento. & 5 & 2 & 3 & 0 & $15,62 \%$ \\
\hline CET22. Técnicas de gestión de recursos humanos. & 5 & 0 & 3 & 2 & $15,62 \%$ \\
\hline
\end{tabular}

que, de momento, no ha habido modificación de competencias con este cambio. Por tanto, el estudio se rige por las competencias inicialmente establecidas en las guías docentes. 


\begin{tabular}{|c|c|c|c|c|c|}
\hline CET14. Técnicas de gestión administrativa. & 4 & 1 & 3 & 0 & $12,5 \%$ \\
\hline CET15. Técnicas de marketing. & 4 & 1 & 3 & 3 & $12,5 \%$ \\
\hline CET17. Técnicas de adquisición. & 4 & 1 & 3 & 0 & $12,5 \%$ \\
\hline CET18. Técnicas de gestión micro económica. & 4 & 0 & 3 & 1 & $12,5 \%$ \\
\hline CET12. Tecnologías de la información: Telecomunicaciones. & 3 & 0 & 2 & 1 & $9,37 \%$ \\
\hline CET16. Técnicas comerciales. & 2 & 0 & 2 & 0 & $6,25 \%$ \\
\hline CET6. Preservación, conservación, y tratamiento físico de documentos. & 1 & 1 & 0 & 0 & $3,12 \%$ \\
\hline
\end{tabular}

En la primera columna de la tabla 2, se muestran tres competencias con mayor número de apariciones en el total de las asignaturas del grado: CET1. Interacción con los productores, los usuarios y los clientes de la información; CET10. Elaboración y difusión de la información y CET4. Identificación, autentificación y evaluación de fuentes y recursos de información.

Cabe destacar que las competencias CET11. Tecnologías de la información: informática y CET12. Tecnologías de la información: Telecomunicaciones no aparecen en los primeros niveles de concurrencia. La primera aparece en cero asignaturas de formación básica, en 8 asignaturas de formación obligatoria y en 3 asignaturas optativas. La segunda aparece en cero asignaturas de formación básica, en 2 asignaturas obligatorias y en 1 asignatura optativa.

Las competencias CET16. Técnicas comerciales y CET6. Preservación, conservación, y tratamiento físico de documentos, aparecen en los niveles más bajos de concurrencia.

Las competencias con mayor concurrencia, en asignaturas de Formación básica, son CET2. Conocimiento del entorno profesional de la información y la documentación y le sigue CET1. Interacción con los productores, los usuarios y los clientes de la información.

Las competencias con mayor concurrencia en asignaturas Obligatorias son: CET4. Identificación, autentificación y evaluación de fuentes y recursos de información; CET9. Búsqueda y recuperación de la información; CET11. Tecnologías de la información: informática y CET21. Técnicas de diagnóstico y evaluación.

Las competencias con mayor concurrencia en asignaturas Optativas son: CET10. Elaboración y difusión de la información y CET20. Técnicas de planificación y gestión de proyectos.

\section{Análisis de las competencias del grado de Información y Documentación de la UMU respecto del Libro Blanco (ANECA, 2004): adecuación de créditos.}

Tabla 3: Número de créditos de las asignaturas troncales del grado respecto de las recomendaciones dadas en los contenidos comunes obligatorios (troncales) del

Libro Blanco (ANECA, 2004).

\begin{tabular}{|c|c|c|c|c|}
\hline \multirow[t]{2}{*}{$\begin{array}{l}\text { Libro Blanco Grado en Información y Documentación } \\
\text { (ANECA, 2004): competencias }\end{array}$} & \multirow[t]{2}{*}{$\mathbf{L B}$} & \multicolumn{3}{|c|}{$\begin{array}{c}\text { Grado en Información y Documentación } \\
\text { (UMU) }\end{array}$} \\
\hline & & FB+Obl. & Optati. & Total \\
\hline
\end{tabular}




\begin{tabular}{|c|c|c|c|c|}
\hline CET21. Técnicas de diagnóstico y evaluación & 90 & 90 & 12 & 102 \\
\hline CET09. Búsqueda y recuperación de información & 66 & 102 & 6 & 108 \\
\hline CET10. Elaboración y difusión de la información & 48 & 108 & 30 & 138 \\
\hline CET11. Tecnologías de la información: informática & 60 & 120 & 6 & 126 \\
\hline CET05. Gestión de colecciones y fondos & 54 & 102 & 6 & 108 \\
\hline CET08. Organización y almacenamiento de la información & 54 & 90 & 18 & 108 \\
\hline CET07. Análisis y representación de la información & 54 & 72 & 18 & 90 \\
\hline CET04. Identificación, autentificación y evaluación de recursos de información & 48 & 114 & 24 & 138 \\
\hline CET01. Interacción con los productores, los usuarios y los clientes de la información & 48 & 108 & 42 & 132 \\
\hline CET06. Preservación, conservación y tratamiento físico de docs. & 42 & 6 & 0 & 6 \\
\hline CET20. Técnicas de planificación y gestión de proyectos & 24 & 24 & 30 & 54 \\
\hline CET14. Técnicas de gestión administrativa & 24 & 18 & 0 & 18 \\
\hline CET23. Técnicas de formación & 24 & 42 & 24 & 54 \\
\hline CET12. Tecnologías de la información: telecomunicaciones & 24 & 24 & 6 & 30 \\
\hline CET13. Técnicas de producción y edición & 24 & 36 & 18 & 54 \\
\hline CET15. Técnicas de márketing & 24 & 36 & 0 & 36 \\
\hline CET19. Técnicas de instalación, acondicionamiento y equipamiento & 24 & 42 & 0 & 42 \\
\hline CET22. Técnicas de gestión de recursos humanos & 24 & 24 & 12 & 36 \\
\hline CET16. Técnicas comerciales & 24 & 18 & 0 & 18 \\
\hline CET17. Técnicas de adquisición & 24 & 36 & 0 & 36 \\
\hline CET18. Técnicas de gestión micro económica & 24 & 24 & 6 & 30 \\
\hline CET02. Conocimiento del entorno profesional de la información..... & 12 & 60 & 6 & 66 \\
\hline CET03. Conocimiento del marco jurídico y administrativo nacional & 12 & 48 & 0 & 48 \\
\hline
\end{tabular}

La tabla 3 muestra la adecuación recomendada de competencias, en número de créditos, propuestos por el Libro Blanco (ANECA, 2004) y los asignados para cada asignatura del grado en la modalidad $\mathrm{Fb}+\mathrm{Obl}$ y Optativa.

La competencia CET10. Elaboración y difusión de la información aparece en 7 asignaturas obligatorias, en 6 asignaturas de formación básica y en 5 asignaturas optativas. Asignando 108 créditos a formación básica - obligatoria y 30 créditos a optativas cuando el Libro Blanco recomienda para esta competencia, en los contenidos comunes obligatorios (troncales) 66 créditos en materias tales como: Fuentes de información 12 créditos, Representación y recuperación de la información 36 créditos y Gestión técnica de documentos de archivo 18 créditos.

De la misma manera pasa con la competencia CET04. Identificación, autentificación y evaluación de fuentes, esta aparece en 8 asignaturas obligatorias, en 3 de formación básica y en 4 optativas. Asignando 114 créditos a formación básica - obligatoria y 24 a optativas cuando el Libro Blanco recomienda para esta competencia, en los contenidos comunes obligatorios (troncales) 48 créditos en materias tales como: Fuentes de información 12 créditos, Gestión técnica de documentos de archivo 36 créditos y en Estudios métricos de información y Fundamentos y metodologías de investigación 18 créditos.

La competencia CET06. Preservación, conservación y tratamiento físico de documentos aparece solamente en 1 asignatura de formación básica. Asignando 6 créditos cuando el Libro Blanco recomienda para esta competencia, en los 
contenidos comunes obligatorios (troncales) 42 créditos en materias tales como: Planificación, organización y evaluación de unidades de información 24 créditos y Gestión técnica de documentos de archivo 18 créditos. La competencia CET14. Técnicas de gestión administrativa aparece en 4 asignaturas de formación básica - obligatorias. Asignando 18 créditos cuando el Libro Blanco recomienda para esta competencia, en los contenidos comunes obligatorios (troncales) 24 créditos en materias como: Planificación, organización y evaluación de unidades de información 24 créditos.

Llama la atención que la competencia CET02. Conocimiento del entorno profesional de la información aparezca en 2 asignaturas obligatorias, 8 asignaturas de formación básica y 1 optativa, asignando 66 créditos cuando el Libro Blanco recomienda para esta competencia, en los contenidos comunes obligatorios (troncales) 12 créditos en materias tales como: Documentos, unidades y sistemas de información. Lo mismo pasa con la competencia CETO3. Conocimiento del marco jurídico y administrativo nacional, aparece en 2 asignaturas obligatorias y 3 asignaturas de formación básica, asignando 48 créditos cuando el Libro Blanco recomienda para esta competencia, en los contenidos comunes obligatorios (troncales) 12 créditos.

Finalmente, las competencias que se equiparan son: CET20. Técnicas de planificación y gestión de proyectos; CET12. Tecnologías de la información: telecomunicaciones; CET22. Técnicas de gestión de recursos humanos y CET18. Técnicas de gestión microeconómica en lo referente a asignaturas de formación básica y obligatoria cumplen con las recomendaciones del Libro Blanco en los contenidos comunes obligatorios (troncales), asignando 24 créditos a cada una de ellas.

\section{Análisis de las competencias del grado de Información y Documentación de la UMU respecto del Libro Blanco para el Diseño de Titulaciones Universitarias en el Marco de la Economía Digital (ANECA, 2015).}

El Libro Blanco (ANECA, 2015) refleja las áreas en las que estuvieron trabajando las diferentes comisiones encargadas de elaborar los informes sectoriales que permitieron contar con la información referente a las características de las nuevas titulaciones en el sector de la Economía Digital: tecnología de la Innovación; diseño visual, arte y creatividad; estrategia y gestión de negocio.

Las siguientes tablas muestran la posible vinculación de las competencias específicas establecidas en el grado de Información y Documentación de la Universidad de Murcia con aquellas competencias que, en ciertos aspectos, se adecuan a las mismas. El carácter tan genérico de las competencias del grado en Información y Documentación nos ha permitido establecer la trayectoria de la evolución de cada una de las competencias definidas, con un carácter general, hacia un carácter más específico dentro de las competencias propuestas por el Libro Blanco (ANECA, 2015).

En cada área se han establecido el conjunto de competencias específicas afines del Libro Blanco (ANECA, 2015) permitiendo definir categorías de las mismas, deducidas de las competencias específicas iniciales establecidas en el grado de Información y Documentación y del Libro Blanco (ANECA, 2004), así como de los principios rectores que rige nuestra disciplina. 
Las categorías establecidas detectadas para cada una de las áreas: tecnología de la innovación; arte, diseño y creatividad; estrategia y gestión de negocio son:
A. Entorno competencial
B. Regulación
C. Aspectos técnicos y formales de la informática
D. Documentar el contexto de la gestión de información
E. Tratamiento de la información

Tabla 4: Número de competencias específicas asignadas a cada categoría dentro de cada área establecida por el LB (ANECA, 2015)

\begin{tabular}{|l|c|c|c|c|c|}
\hline \multicolumn{1}{|c|}{ Áreas } & \multicolumn{5}{c|}{ Categorías } \\
\hline & A & B & C & D & E \\
\hline 1. Tecnología de la innovación & 1 & 2 & 4 & 10 & 8 \\
\hline 2. Arte, diseño y creatividad & & & 2 & 3 & 2 \\
\hline 3. Estrategia y Gestión de negocio & & 1 & & 5 & 1 \\
\hline
\end{tabular}

\section{Área 1: Tecnología de la Innovación}

\section{Entorno competencial}

\section{Competencias específicas (grado en Información y Documentación UMU)}

CET1. Interacción con los productores, los usuarios y los clientes de la información.

CET2. Conocimiento del entorno profesional de la información y la documentación.

CET18. Técnicas de gestión micro económica. Controlar y optimizar de forma permanente los recursos del organismo y su utilización.

\section{Competencias específicas del Libro Blanco (ANECA, 2015)}

CE1. Conocer, comprender y evaluar las tendencias en el mercado de la

Economía Digital, así como estimar su impacto en el desarrollo social, económico y cultural.

Tabla 5: Derivación de competencias específicas del GIyD a nuevos conocimientos disciplinares en la categoría «entorno competencial» en el mercado de la Economía Digital (1er área).

\begin{tabular}{|c|c|}
\hline Conocimientos disciplinares & Competencias específicas Libro Blanco (ANECA, 2004) \\
\hline • Características, mercados e impacto de la Economía Digital. & $\begin{array}{l}\text { Interacción usuarios y clientes de la información. } \\
\text { - Entorno profesional de la información y la } \\
\text { documentación. }\end{array}$ \\
\hline
\end{tabular}

\section{Regulación}

Competencias específicas (grado en Información y Documentación UMU)

CET3. Conocimiento del marco jurídico y administrativo nacional e internacional de la gestión de información.

\section{Competencias específicas del Libro Blanco (ANECA, 2015)}

CE2. Identificar, conocer y comprender los marcos regulatorios, las organizaciones de referencia y los estándares y recomendaciones existentes en el ámbito de las redes y servicios digitales. 
CE3. Conocer la legislación en materia de datos personales, privacidad y derechos fundamentales de las personas, interoperabilidad, propiedad intelectual $\mathrm{y}$ reutilización de datos.

Tabla 6: Derivación de competencias específicas del GIyD a nuevos conocimientos disciplinares en la categoría «regulación» en el mercado de la Economía Digital (1er área).

\begin{tabular}{|l|l|}
\hline \multicolumn{1}{|c|}{ Conocimientos disciplinares } & \multicolumn{1}{|c|}{ Competencias específicas Libro Blanco (ANECA, 2004) } \\
\hline - Marco regulatorio de las redes y servicios digitales. & $\bullet \quad$ Marco jurídico. \\
- Organizaciones de referencia de las redes y servicios digitales. & $\bullet \quad \begin{array}{l}\text { Regulación de los nuevos soportes de la gestión de } \\
\text { información. }\end{array}$ \\
\hline
\end{tabular}

\section{Aspectos técnicos y formales de la informática}

\section{Competencias específicas (grado en Información y Documentación UMU)}

CET11. Tecnologías de la información: informática. Utilizar y poner en práctica métodos, técnicas y herramientas informáticas (hardware o software) para la implantación, desarrollo y explotación de sistemas de información.

CET12. Tecnologías de la información: telecomunicaciones. Utilizar y poner en práctica los métodos, las técnicas y las herramientas (hardware o software) para la implantación, desarrollo y explotación de sistemas de telecomunicación.

\section{Competencias específicas del Libro Blanco (ANECA, 2015)}

CE4. Conocer los fundamentos básicos, los principios y las aplicaciones de los sistemas informáticos, el tratamiento masivo de datos, el desarrollo software de aplicación y embebido, la electrónica y las redes de comunicaciones.

CE5. Comprender las diferentes tecnologías, elementos y arquitecturas que intervienen en los servicios esenciales de las redes digitales, alcanzando una visión global de los diferentes aspectos que condicionan su prestación: calidad, disponibilidad, interoperabilidad, etc.

CE6. Comprender los diferentes aspectos involucrados en la seguridad de las redes y los servicios prestados sobre redes digitales.

CE7. Conocer los fundamentos básicos de las tecnologías esenciales implicadas en un centro de datos: procesamiento en la nube, virtualización, definición software de redes, virtualización de funciones de red (si vamos a analizar datos almacenados, debemos conocer los soportes).

Tabla 7: Derivación de competencias específicas del GIyD a nuevos conocimientos disciplinares en la categoría «aspectos técnicos y formales de la informática» en el mercado de la Economía Digital (1er área).

\begin{tabular}{|c|c|}
\hline Conocimientos disciplinares & Competencias específicas Libro Blanco (ANECA, 2004) \\
\hline 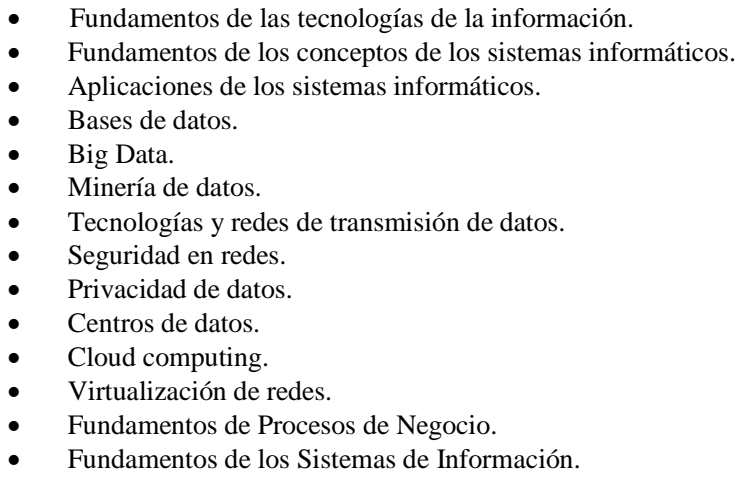 & $\begin{array}{l}\text { - } \quad \text { Informática. } \\
\text { - Sistemas de Información. }\end{array}$ \\
\hline
\end{tabular}


- $\quad$ Fundamentos de BPM (Business Process Management).

- $\quad$ Lenguaje BPMN (Business Process Management Notation).

- Herramientas de Diseño y Monitorización de Procesos.

\section{Documentar el contexto de la gestión de la información}

\section{Competencias específicas (grado en Información y Documentación UMU)}

CET1. Interacción con los productores, los usuarios y los clientes de la información. Analizar e interpretar las prácticas, las demandas, las necesidades y las expectativas de los productores, los usuarios y los clientes, actuales y potenciales, y desarrollar su cultura de la información ayudándoles a hacer mejor uso de los recursos disponibles.

CET20. Técnicas de planificación y gestión de proyectos. Prever, organizar, gestionar y llevar a buen término un proyecto técnico integrando las limitaciones del entorno: humanas, económicas, de calendario, reglamentarias.

CET21. Técnicas de diagnóstico y evaluación. Identificar los puntos fuertes y débiles de una organización, de un producto o de un servicio, establecer y utilizar indicadores, elaborar soluciones para mejorar la calidad.

\section{Competencias específicas Libro Blanco (ANECA, 2015)}

CE8. Conocer y comprender los fundamentos de la gestión integral de la producción y los sistemas para la industria 4.0 y los sistemas CPS.

CE9. Conocer y utilizar los modelos de tipos de datos y los algoritmos y técnicas de gestión asociadas a los mismos

CE10. Comprender las técnicas de sistemas de gestión de bases de datos, tanto estructuradas como no estructuradas, monolíticas y distribuidas.

CE11. Comprender las técnicas de ingeniería de sistemas de información a los procesos de negocio

CE12. Desarrollar la implementación y puesta en marcha de proyectos en el ámbito de sistemas de gran volumen de datos.

CE13. Definir e implementar los procedimientos de gestión operativa de sistemas de gran volumen de datos.

CE14. Comprender la modelización y evaluación de servicios en base a criterios de capacidad, utilización y calidad de servicio.

CE15. Conocer y utilizar los sistemas de cuadro de mando y ayuda a la decisión, y sistemas y técnicas de modelización y simulación.

CE16. Conocer y utilizar los estándares y técnicas de datos abiertos (open data) para su aprovechamiento como usuarios (consumidores) y como proveedores (productores)

CE17. Conocer y utilizar los modelos y estándares del ámbito de los sistemas de grandes volúmenes de datos.

Tabla 8: Derivación de competencias específicas del GIyD a nuevos conocimientos disciplinares en la categoría «documentar el contexto de la gestión de la información» en el mercado de la Economía Digital (1er área).

\begin{tabular}{|l|r|}
\hline \multicolumn{1}{|c|}{ Conocimientos profesionales } & $\begin{array}{c}\text { Competencias específicas Libro Blanco (ANECA, } \\
\text { 2004) }\end{array}$ \\
\hline • $\begin{array}{l}\text { Industria 4.0 (Industria inteligente o Ciber-industria del } \\
\text { futuro). }\end{array}$ & $\bullet \begin{array}{l}\text { Productores, los usuarios y los clientes de } \\
\text { la información. }\end{array}$ \\
- Sistemas ciber-físicos (CPS). & $\begin{array}{l}\text { Técnicas de planificación y gestión de } \\
\text { proyectos. }\end{array}$ \\
- $\begin{array}{l}\text { Big Data. } \\
\text { - Smart cities. }\end{array}$ & $\bullet \quad$ Técnicas de diagnóstico y evaluación. \\
\hline
\end{tabular}


- Gestión integrada.

- Fundamentos de la Ciencia de los Datos.

- Fundamentos de XML (Extensible Markup Language).

- Definición de Modelos de Datos.

- Algoritmos de Extracción de Información.

- Técnicas de Inteligencia Artificial para el Análisis de datos.

- Sistemas de Gestión de Información.

- Técnicas de Diseño de Bases de Datos Robustas.

- Bases de Datos Estructuradas.

- Bases de Datos Monolíticas.

- Bases de Datos Distribuida.

- Herramientas de Modelado de Datos.

- Fundamentos de Proyectos de Big Data.

- Integridad y Optimización de la Información almacenada en la nube.

- Calidad del Servicio.

- Evaluación de Servicios de Información.

- Disponibilidad del Servicios.

- ITIL, Biblioteca de Infraestructuras de Tecnologías de Información

- ISO2000.

- Capacidad del Servicio.

- Métricas para Servicios de TI

- Concepto de Cuadro de Mando.

- Diseño de Cuadros de Mando.

- Herramientas para la generación de Cuadros de Mando.

- Sistemas de Apoyo a la Toma de Decisiones.

- Técnicas de Simulación: Analítica y Digital.

- Herramientas de Simulación.

- Fundamentos de Open Data.

- Formatos de Open Data.

- Desarrollo de Aplicaciones.

- Linking Open Data.

- Reutilización de la Información.

- Liberación de los Datos.

- Normativa Vigente del uso de Open Data.

- Modelos y Estándares de Almacenamientos de Datos.

- Fundamentos de NoSQL.

- Tendencias en la estandarización de Grandes Volúmenes de Datos.

- Soluciones empresariales para la Gestión Masiva de Información.

- Cloud Database

\section{Tratamiento de la información}

\section{Competencias específicas (grado en Información y Documentación UMU)}

CET1. Interacción con los productores, los usuarios y los clientes de la información. Analizar e interpretar las prácticas, las demandas, las necesidades y las expectativas de los productores, los usuarios y los clientes, actuales y potenciales, y desarrollar su cultura de la información ayudándoles a hacer mejor uso de los recursos disponibles. 
CET7. Análisis y representación de la información. Identificar y representar en el lenguaje documental adoptado o en otro sistema simbólico el contenido semántico de un documento o de una colección de documentos o de un fondo de archivo.

CET8. Organización y almacenamiento de la información. Organizar y estructurar los datos relativos a la descripción de documentos y colecciones de documentos en cualquier soporte; crear y explotar las herramientas de acceso a los datos, documentos o referencias.

CET9. Búsqueda y recuperación de la información. Buscar y recuperar la información por métodos que permitan dar respuesta a las expectativas de los demandantes en condiciones óptimas de coste y tiempo.

CET10. Elaboración y difusión de la información. Hacer disponibles y explotables las informaciones tratadas y facilitar su uso mediante el suministro de productos y servicios documentales.

\section{Competencias específicas Libro Blanco (ANECA, 2015)}

CE18. Redactar, clasificar e interpretar documentación técnica del ámbito de las redes digitales

CE19. Comprender las técnicas de implementación y explotación de bases de datos de gran tamaño, distribuidas y escalables.

CE20. Comprender las técnicas de gestión de datos propias de big data para la captación y almacenamiento de datos.

CE21. Conocer y utilizar las técnicas matemáticas y estadísticas para el tratamiento de datos.

CE22. Conocer y utilizar las tipologías y técnicas de representación gráfica y analítica de información compleja.

CE23. Comprender las arquitecturas y técnicas propias de big data para la gestión de datos estáticos y dinámicos, estructurados y no estructurados, y tanto para algoritmos descriptivos, predictivos y prescriptivos.

CE24. Conocer y utilizar las técnicas de desarrollo de aplicaciones de gestión de grandes volúmenes de datos.

CE25. Comprender, utilizar y desarrollar la gestión de metadatos en sistemas, bases de datos, documentos, aplicaciones y servicios.

CE26. Confeccionar e interpretar documentación técnica en materia de sistemas de gran volumen de datos.

Tabla 9: Derivación de competencias específicas del GIyD a nuevos conocimientos profesionales en la categoría «tratamiento de la información» en el mercado de la Economía Digital (1er área).

\begin{tabular}{|c|c|}
\hline Competencias profesionales & $\begin{array}{l}\text { Competencias específicas Libro Blanco (ANECA, } \\
\text { 2004) }\end{array}$ \\
\hline 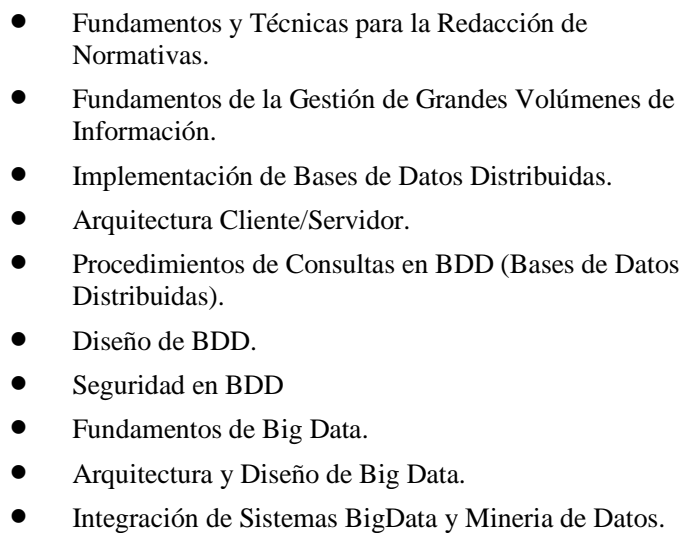 & $\begin{array}{l}\text { - Productores, los usuarios y los clientes de } \\
\text { - } \text { la información } \\
\text { - Aúsqueda de información. } \\
\text { - Organisis y representación de información. } \\
\text { - } \text { información. } \\
\text { - Elaboración y difusión de la información. }\end{array}$ \\
\hline
\end{tabular}


- Privacidad y Seguridad de Big Data.

- Cloud Databases

- Fundamentos de Estadística.

- Introducción a la Probabilidad.

- Distribución en el Muestreo.

- Hipótesis y Contraste.

- Métodos de captura y almacenamiento de la información.

- Análisis e interpretación de datos.

- Análisis Bayesianos de grandes conjuntos de Datos.

- Fundamentos de la Visualización.

- Cognición. Hadoop.

- Herramientas de Hadoop (para procesar Big Data).

- Fundamentos de Virtualización y Seguridad.

- Arquitecturas Distribuidas.

- Programación Distribuida.

- Bases de Datos no convencionales.

- Paralelización de de Datos

- Fundamentos de los Metadatos.

- XML.

- Infreatructura del Dato.

- Uso más comunes de los Metadatos.

- Desarrollo de Aplicaciones Seguras mediante el Catálogo de Metadatos.

- Trazabilidad del Dato

- Conocimiento de la Normativa Vigente.

- Redacción de Normativas y Estándares.

- Análisis y Nomenclatura de Pliegos Específicos.

\section{Área 2: Arte, diseño y creatividad}

\section{Aspectos técnicos y formales de la informática}

\section{Competencias específicas (grado en Información y Documentación UMU)}

CET11. Tecnologías de la información: informática. Utilizar y poner en práctica métodos, técnicas y herramientas informáticas (hardware o software) para la implantación, desarrollo y explotación de sistemas de información.

\section{Competencias específicas Libro Blanco (ANECA, 2015)}

CE27. Conocer los principios básicos de programación de los ordenadores.

CE28. Apreciar los valores formales, semánticos, funcionales y ergonómicos del diseño.

Tabla 10: Derivación de competencias específicas del GIyD a nuevos conocimientos disciplinares en la categoría «aspectos técnicos y formales de la informática» en el mercado de la Economía Digital (2 área).

\begin{tabular}{|c|c|}
\hline Competencias disciplinares & $\begin{array}{l}\text { Competencias específicas Libro Blanco (ANECA, } \\
\text { 2004) }\end{array}$ \\
\hline 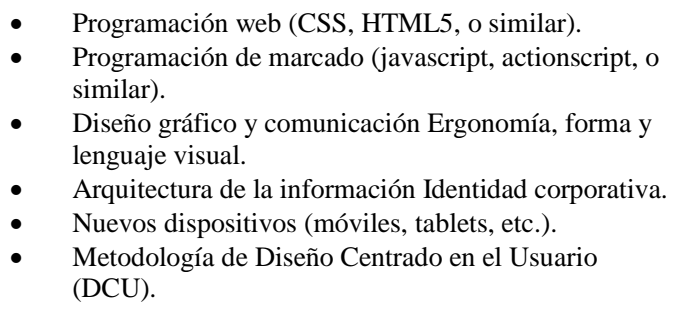 & - Informática. \\
\hline
\end{tabular}




\section{Documentar el contexto de la gestión de información}

\section{Competencias específicas (grado en Información y Documentación UMU)}

CET1. Interacción con los productores, los usuarios y los clientes de la información. Analizar e interpretar las prácticas, las demandas, las necesidades y las expectativas de los productores, los usuarios y los clientes, actuales y potenciales, y desarrollar su cultura de la información ayudándoles a hacer mejor uso de los recursos disponibles.

CET20. Técnicas de planificación y gestión de proyectos. Prever, organizar, gestionar y llevar a buen término un proyecto técnico integrando las limitaciones del entorno: humanas, económicas, de calendario, reglamentarias.

CET21. Técnicas de diagnóstico y evaluación. Identificar los puntos fuertes y débiles de una organización, de un producto o de un servicio, establecer y utilizar indicadores, elaborar soluciones para mejorar la calidad.

CET15. Técnicas de marketing. Analizar y situar la actividad en un contexto estratégico y de competencia; promover dicha actividad elaborando y poniendo a punto las herramientas de trabajo apropiadas para la captación del mercado.

CET16. Técnicas comerciales. Establecer y mantener relaciones con clientes o socios con el fin de vender productos y servicios.

\section{Competencias específicas Libro Blanco (ANECA, 2015)}

CE29.Saber analizar de forma general un contexto, y en base a los datos recogidos tomar decisiones sobre el proyecto digital, relacionados con el público objetivo del mismo y el modelo de negocio establecido.

CE30. Poseer conocimientos básicos de economía, marketing y comercialización para la gestión del proyecto.

CE31. Poseer conocimientos básicos de gestión de proyectos de los procesos de diseño y desarrollo de un producto digital.

Tabla 11: Derivación de competencias específicas del GIyD a nuevos conocimientos disciplinares en la categoría «documentar el contexto de la gestión de información» en el mercado de la Economía Digital (2 $2^{a}$ área).

\begin{tabular}{|c|c|}
\hline Conocimientos disciplinares & $\begin{array}{c}\text { Competencias específicas Libro Blanco } \\
\text { (ANECA, 2004) }\end{array}$ \\
\hline $\begin{array}{l}\text { - } \quad \text { Diseño web y target. } \\
\text { - } \quad \text { Diseño publicitario y target. } \\
\text { - } \quad \text { Gestión de proyectos de diseño. } \\
\text { - } \quad \text { Herramion de proyectos editoriales en el ámbito digital. } \\
\text { (Project, DPS, o similar). } \\
\text { - Herramientas de gestión y publicación de contenidos } \\
\text { (CMS o similar). }\end{array}$ & 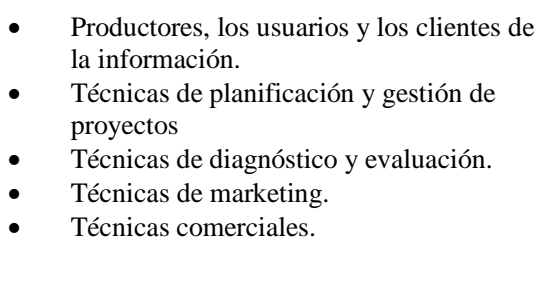 \\
\hline
\end{tabular}

\section{Tratamiento de la información}

\section{Competencias específicas (grado en Información y Documentación UMU)}

CET1. Interacción con los productores, los usuarios y los clientes de la información. Analizar e interpretar las prácticas, las demandas, las necesidades y las expectativas de los productores, los usuarios y los clientes, actuales y potenciales, y desarrollar su cultura de la información ayudándoles a hacer mejor uso de los recursos disponibles.

CET7. Análisis y representación de la información. Identificar y representar en el lenguaje documental adoptado o en otro sistema simbólico el contenido semántico de un documento o de una colección de documentos o de un fondo de archivo. 
CET13. Técnicas de producción y edición. Producir o reproducir documentos en cualquier soporte y formato con vistas a su difusión.

\section{Competencias específicas Libro Blanco (ANECA, 2015)}

CE32. Conocer y aplicar las técnicas y las herramientas artísticas asociadas a la generación de contenidos digitales.

CE33. Diseñar y planificar una página web compleja y completamente operativa.

Tabla 12: Derivación de competencias específicas del GIyD a nuevos conocimientos profesionales en la categoría «tratamiento de la información» en el mercado de la Economía Digital ( ${ }^{\mathrm{a}}$ área).

\begin{tabular}{|l|c|}
\hline \multicolumn{1}{|c|}{ Competencias profesionales } & $\begin{array}{c}\text { Competencias específicas Libro Blanco (ANECA, } \\
\text { 2004) }\end{array}$ \\
\hline - $\begin{array}{l}\text { Aplicación de herramientas de diseño y desarrollo de } \\
\text { páginas web (Dreamweaver, Flash, Photoshop, After }\end{array}$ & - $\begin{array}{l}\text { Productores, los usuarios y los clientes de } \\
\text { la información. }\end{array}$ \\
$\begin{array}{l}\text { Effects, FireWorks, WordPress,.). } \\
\text { Diseño de una web. }\end{array}$ & - Análisis y representación de información. \\
- $\begin{array}{l}\text { Técnicas de planificación y gestión de } \\
\text { proyectos. }\end{array}$ \\
Desarrolión de un proyecto web.
\end{tabular}

\section{Área 3: Estrategia y Gestión de negocio}

\section{Regulación}

\section{Competencias específicas (grado en Información y Documentación UMU)}

CET3. Conocimiento del marco jurídico y administrativo nacional e internacional de la gestión de información.

\section{Competencias específicas Libro Blanco (ANECA, 2015)}

CE34. Conocer los mecanismos legislativos de incidencia en el negocio digital de forma teórico-práctica: conocimiento del entorno legal básico de los negocios digitales, así como de la nomenclatura y estructura de los contratos más habituales, como por ejemplo confidencialidad, propiedad intelectual, o comercialización y pagos online.

Tabla 13: Derivación de competencias específicas del GIyD a nuevos conocimientos disciplinares en la categoría «Regulación» en el mercado de la Economía Digital (3er área).

\begin{tabular}{|c|c|}
\hline Competencias disciplinares & Competencias específicas Libro Blanco (ANECA, 2004) \\
\hline $\begin{array}{l}\text { - } \quad \text { Regulación digital. } \\
\text { - } \quad \text { Propiedad Intelectual. } \\
\text { - } \\
\text { - } \\
\text { Derechribución de conten Internet. } \\
\text { Regulación en el ámbito de los medios sociales. }\end{array}$ & $\begin{array}{l}\text { - Regulación de los nuevos soportes de la gestión } \\
\text { de información. }\end{array}$ \\
\hline
\end{tabular}

\section{Documentar el contexto de gestión de información}

\section{Competencias específicas (Grado en Información y Documentación UMU)}

CET1. Interacción con los productores, los usuarios y los clientes de la información. Analizar e interpretar las prácticas, las demandas, las necesidades y las expectativas de los productores, los usuarios y los clientes, actuales y potenciales, y desarrollar su cultura de la información ayudándoles a hacer mejor uso de los recursos disponibles.

CET20. Técnicas de planificación y gestión de proyectos. Prever, organizar, gestionar y llevar a buen término un proyecto técnico integrando las limitaciones del entorno: humanas, económicas, de calendario, reglamentarias. 
CET21. Técnicas de diagnóstico y evaluación. Identificar los puntos fuertes y débiles de una organización, de un producto o de un servicio, establecer y utilizar indicadores, elaborar soluciones para mejorar la calidad.

CET15. Técnicas de marketing. Analizar y situar la actividad en un contexto estratégico y de competencia; promover dicha actividad elaborando y poniendo a punto las herramientas de trabajo apropiadas para la captación del mercado.

CET16. Técnicas comerciales. Establecer y mantener relaciones con clientes o socios con el fin de vender productos y servicios.

\section{Competencias específicas Libro Blanco (ANECA, 2015)}

CE35. Conocer el ciclo de vida completo de un proyecto en desarrollo y comercialización de contenidos digitales: conocimiento de las etapas que componen un proyecto de contenidos digitales, desde la prospección comercial e inteligencia de negocio, hasta la analítica de resultados tras la etapa de distribución.

CE36. Definir y gestionar el nivel de servicio: capacidad para diseñar y mantener un servicio satisfactorio para el usuario digital, mediante canales de información, soporte y comunicación adecuados al servicio y/o producto distribuido.

CE37. Planificar la gestión de proyectos en relación con los contenidos y la economía digital: capacidad para planificar y supervisar proyectos en relación con la comercialización digital, incluyendo las metodologías y procesos más habituales en la industria.

CE38. Planificar la arquitectura del Sistema de Información online: capacidad para definir los canales de gestión de la información digital, desde las fuentes, hasta el almacenamiento y la transmisión de esa información entre los diversos equipos.

CE39. Definir el proceso de apoyo al usuario digital en el suministro de servicio: capacidad para diseñar y mantener un sistema de atención al usuario digital, con el fin de facilitar información sobre servicios, reportar incidencias, y tramitar transacciones individualizadas como devoluciones.

Tabla 14: Derivación de competencias específicas del GIyD a nuevos conocimientos disciplinares en la categoría «Documentar el contexto de gestión de información» en el mercado de la Economía Digital (3er área).

\begin{tabular}{|c|c|}
\hline Competencias disciplinares & Competencias específicas Libro Blanco (ANECA, 2004) \\
\hline $\begin{array}{ll}\text { - } & \text { Creación y distribución de contenidos digitales. } \\
\text { - } & \text { Desarrollo de proyectos. } \\
\text { - } & \text { Diseño y gestión de contenidos. } \\
\text { - } & \text { Plataformas digitales. } \\
\text { - } & \text { Expericas de rendimiento. } \\
\text { - } & \text { ORM (Online Reputation Management). } \\
\text { - } & \text { Medición, monitorización. } \\
\text { - } & \text { Métricas de nivel de servicio. } \\
\text { - } & \text { Experiencia del usuario. } \\
\text { - } & \text { Gestión de contenidos digitales. } \\
\text { - } & \text { Usabilidad y Arquitectura web. } \\
\text { - } & \text { Desarrollo de aplicaciones. } \\
\text { - } & \text { Sistemas de atención al cliente. } \\
\text { - } & \text { CRM (Customer Relationship Management). }\end{array}$ & $\begin{array}{l}\text { - } \quad \text { Productores, los usuarios y los clientes de la } \\
\text { información. } \\
\text { - Técnicas de planificación y gestión de proyectos. } \\
\text { - Técnicas de diagnóstico y evaluación. } \\
\text { - Técnicas de marketing. } \\
\text { - Técnicas de comerciales. }\end{array}$ \\
\hline
\end{tabular}

\section{Tratamiento de la información}

Competencias específicas (grado en Información y Documentación UMU) 
CET4. Identificación, autenticación y evaluación de fuentes y recursos de información. Identificar, evaluar y validar informaciones, documentos y sus fuentes, tanto internas como externas.

CET9. Búsqueda y recuperación de la información. Buscar y recuperar la información por métodos que permitan dar respuesta a las expectativas de los demandantes en condiciones óptimas de coste y tiempo.

CET10. Elaboración y difusión de la información. Hacer disponibles y explotables las informaciones tratadas y facilitar su uso mediante el suministro de productos y servicios documentales.

CET15. Técnicas de marketing. Analizar y situar la actividad en un contexto estratégico y de competencia; promover dicha actividad elaborando y poniendo a punto las herramientas de trabajo apropiadas para la captación del mercado.

CET16. Técnicas comerciales. Establecer y mantener relaciones con clientes o socios con el fin de vender productos y servicios.

\section{Competencias específicas Libro Blanco (ANECA, 2014)}

CE44. Gestionar grandes cantidades de información o Big Data: capacidad para sintetizar, filtrar y extraer información relevante a partir de cantidades de información elevadas, de manera que puedan servir como referencia para procesos de tomas de decisión en economía digital.

Tabla 15: Derivación de competencias específicas del GIyD a nuevos conocimientos disciplinares en la categoría «tratamiento de la información» en el mercado de la Economía Digital (3er área).

\begin{tabular}{|l|r|}
\hline \multicolumn{1}{|c|}{ Competencias disciplinares } & Competencias específicas Libro Blanco (ANECA, 2004) \\
\hline $\begin{array}{l}\text { Big Data para la creación de productos y } \\
\text { servicios digitales. }\end{array}$ & $\begin{array}{l}\text { Búsqueda de información y recuperación de } \\
\text { información. }\end{array}$ \\
& $\begin{array}{l}\text { Evaluación de recursos de información. } \\
\end{array}$ \\
\hline
\end{tabular}

Hay dos categorías que se repiten en las tres áreas establecidas: «documentar el contexto de la gestión de información» y «tratamiento de la información». A la primera categoría se le asignan un total de 10 competencias específicas en el área de tecnología de la innovación, 3 competencias en el área arte, diseño y creatividad y 5 competencias en el área estrategia y gestión de negocio. En la segunda categoría se asignan 8 competencias en el área de tecnología de la innovación, 2 competencias específicas en el área arte, diseño y creatividad y 1 competencia en el área estrategia y gestión de negocio (Tablas 4, 8, 9, 11, 12, 14, $15)$.

Se puede apreciar que el mayor número de competencias específicas de la categoría «documentar el contexto de la gestión información», en el área tecnología de la innovación, deriva de la vinculación de competencias del grado en Información y Documentación (CET1, CET20, CET21) que supone la adquisición de conocimientos profesionales en técnicas que implican la capacidad de estudiar el contexto de la gestión de información como punto de partida, como por ejemplo la fase en la que procede documentar los aspectos funcionales y organizacionales para poder dar una solución coherente de gestión. Para el resto de áreas, implica la adquisición de conocimientos disciplinares en esas mismas categorías (Tablas 8, 11, 14). 
Por otro lado, el mayor número de competencias de la categoría tratamiento de la información, en el área tecnología de la innovación, deriva de la vinculación de competencias del grado en Información y Documentación (CET1, CET7, CET8, CET9, CET10), supone la adquisición de conocimientos profesionales en el proceso informativo - documental, extrapolado a una nueva realidad en el entorno digital. Para el área arte, diseño y creatividad también supone la adquisición de conocimientos profesionales pero para el área estrategia y gestión de negocio conlleva la adquisición de conocimientos disciplinares. (Tablas 9, 11, 15).

La categoría «aspectos técnicos y formales de la informática» tiene presencia en dos áreas: tecnología de la innovación y arte, diseño y creatividad. En la primera área se le asignan 4 competencias y para la segunda 2. El mayor número de competencias específicas en ambos casos deriva de la vinculación de competencias del grado en Información y Documentación (CET11, CET12) que suponen la adquisición de conocimientos disciplinares (Tablas 7,10$)$.

Otra de las categorías establecidas ha sido «regulación», esta tiene presencia en dos áreas: tecnología de la innovación y estrategia y gestión de negocio. A la primera área se le otorgan 2 competencias y para la segunda 1 . El número de competencias específicas en ambos casos deriva de la vinculación de la competencia del grado en Información y Documentación (CET3) que supone la adquisición de conocimientos disciplinares (Tablas 6, 13).

Finalmente, la categoría «entorno competencial» figura únicamente en el área tecnología de la innovación, se le otorga 1 competencia que deriva de la vinculación de las competencias del grado en Información y Documentación (CET1, CET2, CET18) y que supone la adquisición de conocimientos disciplinares (Tabla 5).

Se han seleccionado 16 competencias específicas de las 23 establecidas para el grado de Información y Documentación de la Universidad de Murcia (ANECA, 2004). Analizando esas 16 competencias se detecta un carácter muy genérico que ha permitido clasificar fácilmente los conocimientos de las competencias específicas seleccionadas del Libro Blanco para el Diseño de Titulaciones Universitarias en el Marco de la Economía Digital (ANECA, 2015). Incluso, dentro de las propias competencias específicas del grado, se ha detectado que algunas de ellas pueden ser incluidas dentro de otras mucho más genéricas tales como CET20. Técnicas de planificación y gestión de proyectos, CET21. Técnicas de diagnóstico y evaluación. Esta práctica, por un lado, permite clasificar fácilmente los conocimientos, ya que se consideran grandes cajones de sastre, pero da lugar al vicio de reiteraciones en la clasificación de los conocimientos que el estudiante debe adquirir, tal como se ha comprobado en el análisis de las competencias del grado de Información y Documentación de la UMU respecto del Libro Blanco (2004): adecuación de créditos (Tabla 3).

No se han utilizado 7 de las 23 competencias específicas del grado de Información y Documentación. Estas competencias responden a todos aquellos conocimientos necesarios para trabajar en organismos públicos o privados y que implican la adquisición de conocimientos en la gestión física de la documentación, alejándose de esos conocimientos que propone el Libro Blanco en el Marco de la Economía Digital (ANECA, 2015) y que dan lugar a la gestión de la información en otro tipo de soportes. 


\section{Conclusiones}

Los resultados obtenidos tras la primera fase de análisis demuestran que es necesario una adaptación del grado a la nueva realidad del mercado laboral, y de manera concreta, poner en marcha medidas correctoras que solucionen los déficits observados.

Se observan que dos competencias claves no están en los primeros niveles de concurrencia. La primera, Tecnologías de la Información: Informática tiene presencia en 8 asignaturas obligatorias y la segunda, Tecnologías de la Información: Telecomunicaciones presente en 2 asignaturas obligatorias de las 32 totales que forman el grado. Estas competencias son de suma importancia para formar a los nuevos perfiles profesionales, por el carácter transversal de las mismas sería recomendable revisar las guías docentes de las asignaturas obligatorias y diseñar nuevas asignaturas optativas.

Las competencias con mayor concurrencia en asignaturas obligatorias han sido aquellas centradas en la Búsqueda y Recuperación de Fuentes y Recursos de Información, siendo el principal protagonista el documento como objeto de estudio, seguidas de las competencias Tecnologías de la Información y Técnicas de Diagnóstico y Evaluación con el fin de proporcionar soluciones de calidad de un producto o de un servicio, esta última muy orientada a instituciones documentales.

En esta primera fase de análisis las competencias con los niveles más bajos de concurrencia han sido Preservación y Conservación, Tratamiento Físico del Documento y Técnicas Comerciales, para la primera y segunda competencia se considera necesario reforzar o adaptar los contenidos a la nueva realidad del mercado laboral. Respecto a la tercera de ellas cabria reflexionar sobre su inclusión o no en el plan de estudios ya que no se puede considerar necesaria en perfiles laborares de Información y Documentación.

Evaluando los datos reales disponibles se observa, tras el análisis de las competencias del grado de Información y Documentación de la UMU respecto del Libro Blanco (ANECA, 2004) en cuanto a la adecuación de créditos, que en general existe un excesivo grado de concurrencia de todas las competencias en las asignaturas del grado, en comparativa con las recomendaciones dadas en los contenidos comunes obligatorios (troncales), en número de créditos, propuestos por el Libro Blanco. Esta situación puede deberse a dos causas, que las competencias más desarrolladas en el grado puedan estar indicando un solapamiento de contenidos en distintas asignaturas o que al tener, las competencias, un carácter tan general y básico sean adoptadas en varias guías docentes.

Ha pasado ya más de una década desde la redacción de las competencias para el grado de Información y Documentación, se han cumplido las expectativas del Libro Blanco (ANECA, 2004) y todas ellas tienen una tendencia que se adecua a perfiles de trabajo que actualmente tienen una baja demanda y un grado de obsolescencia en el mercado laboral. Esta tendencia, a lo largo de los años, sumado al carácter transversal de la disciplina en la cobertura a otras áreas de 
conocimiento ha dado lugar, en algunas asignaturas a pequeños cambios pero no lo suficientemente contundentes para adaptarse a las nuevas realidades del mercado laboral. No por ello, las competencias antiguas deben desaparecer sino que simplemente se han quedado obsoletas y es necesario reforzarlas o derivar a competencias más específicas. Lo que no se ha podido comprobar es, si se han desarrollado nuevas competencias internas en aquellas asignaturas donde el principal objeto de estudio cambia y por tanto no figuran en las guías docentes (lo que merecería otro análisis al respecto).

La segunda fase del análisis muestra una categorización de competencias en grandes grupos, haciendo las vinculaciones correspondientes entre las antiguas competencias del grado y algunas de las competencias específicas del Libro Blanco para el Diseño de Titulaciones Universitarias en el Marco de la Economía Digital (ANECA, 2014). Los resultados obtenidos indican que para las categorías «documentar el contexto de la gestión de información» y «tratamiento de la información» debe haber un aumento considerable de las competencias para la adquisición de conocimientos profesionales, vinculados con la estrategia y gestión de negocio y tecnología de la innovación. En este proceso de evolución de competencias el objeto de estudio pasa a ser una plataforma global de información, en el que más allá del uso de TIC, las redes y el uso de datos supone nuevos desarrollos de soluciones emergentes. Los nuevos perfiles deben tener competencias transversales ya que, en los entornos de trabajo de la Economía Digital, hay un marcado carácter multidisciplinar que convive con una alta especialización de los perfiles profesionales.

Esta actuación permitirá demostrar si la situación en la que nos encontramos tiene que ver con la capacidad de adaptar nuestro sello de identidad $\mathrm{y}$, por tanto, centrarnos en lo que nos corresponde por exclusividad. Lo único que ha cambiado es el medio pero «los derechos de autor»son de la Documentación. Se deja la puerta abierta para futuras aportaciones al debate que aquí se pretende iniciar: una disciplina o una ciencia para que tenga identidad y perdurabilidad ¿debe tener unos contenidos que todo el mundo reconozca como exclusivos o propios de ella?.

Adoptar una autoevaluación y autocrítica sobre el manteniendo de nuestro sello de identidad nos llevara a cuestionar cuál fue el propósito inicial de la Documentación, pues nació como la ciencia de la información científica. Ahora toca considerar que conocimientos están en nuestro ratio de enseñanza aprendizaje y eso debe quedar reflejado en el refuerzo de competencias, ya establecidas (con un marcado carácter general que cubrían ese objetivo inicial) y evolucionar hacia un enfoque más específico porque así nos lo demanda el mercado laboral.

\section{Bibliografía}

Abadal, E.; Borrego, Á.; Serra, R. (2012). Mercado laboral de profesionales de la información: evolución de la oferta y de los perfiles ocupacionales. BiD: Textos universitaris de biblioteconomia i documentació, diciembre, 29. Recuperado de https://doi.org/10.1344/BiD2012.29.8 
Abadal, E. (2015). Los retos de la formación en Biblioteconomía y

Documentación. BiD: textos universitaris de biblioteconomia i documentació, 35. Recuperado de https://doi.org/10.1344/BiD2015.35.

Agencia Nacional de Evaluación de la Calidad y Acreditación [España] (2004). Libro blanco: Título de grado en información y documentación. Madrid: Aneca. Recuperado de http://www.aneca.es/var/media/150424/libroblanco_juni05_documentación.p df

Agenda Nacional de Evaluación de la Calidad y Acreditación [España] (2015). Libro Blanco al ámbito de Estrategia y Gestión de Negocio Digital. Madrid: Aneca. Recuperado de http://www.aneca.es/Sala-deprensa/Noticias/2015/ANECA-participa-en-el-Libro-Blanco- para-el-disenode-titulaciones-en-la-Economia-Digital

Agustín, MC y Salvador, JA. (2016). Análisis y evaluación de las competencias de Grado en Información y Documentación en la Universidad de Zaragoza. Education in the Knoeledge society (EKS), 17 (1), 129-146. Recuperado de http://dx.doi.org/10.14201/eks2016171129145

Ala, K. (2011). Mapping Digital Competence: Towards a Conceptual Understanding. Technical Note: JRC 67075 - Joint Research Centre Institute for Prospective Technological Studies. Seville: JRC-IPTS. Recuperado de https://goo.gl/aBl4zv

Álvarez, EP.; Núñez, P.; Rodríguez, C. (2017). Adquisición y carencia académica de competencias tecnológicas ante una economía digital. Revista Latina de Comunicación Social, 72, 540- 559. Recuperado de http://doi.org/10.4185/RLCS-2017-1178

Boisvert, J. (2004). La formación del pensamiento crítico: teórica y práctica. México: Fondo Cultura Económica.

Byrge, C y Hansen, S. (2013) Course in New Thinking in higher education: Enhancing creativity through the means of training, theory and workshop. Problems of Education in the 21st Century, 51(51), 18-32.

Castaño, W.; Múnera, MT.; Uribe, Alejandro. (2018). Hacia dónde debería ir la formación en TIC en la Escuela Interamericana de Bibliotecología. Una mirada a partir de los programas de educación bibliotecológica en America Latina y las tendencias mundiales. Revista Interamericana de Bibliotecología. 41(2), 135-151.

Cobo, C y Moravec, JW. (2011). Aprendizaje invisible. Hacia una nueva ecología de la educación. Razón y Palabra, 77(2). Recuperado de http://www.razonypalabra.org.mx/varia/AprendizajeInvisible.pdf

COIE. Informe de perspectivas profesionales de las personas tituladas en la Universidad de Murcia (2016). Recuperado de http://observatorio.um.es

Elliot, EA y Nakata, C. (2013). Cross-Cultural Creativity: Conceptualization and Propositions for Global New Product Development. The Journal of Product Innovation Management, 30(1), 110-125. Recuperado de http://doi.org/10.1111/jpim.12066

Esteve, F y Gisbert, M. (2011). El nuevo paradigma de aprendizaje y las nuevas tecnologías. Revista de Docencia Universitaria (REDU), 9(3), 55-73. Recuperado de http://doi.org/10.4995/redu

Ferrari, A. (2013). DIGCOMP: A Framework for Developing and Understanding Digital Competence in Europe. Joint Research Centre of the European Commission. Recuperado de http://doi.org/10.2788/52966 
FTI - AMETIC. (2012). PAFET VII. Perfiles Profesionales más demandados en el ámbito de los Contenidos Digitales en España 2012 - 2017. Madrid: Rooter. Recuperado de https://ametic.es/es/publicacione?title=demand

Freire, J y Shuch, K. (2010). Políticas y prácticas para la construcción de una Universidad Digital. La Cuestión Universitaria, 6, 85-94. Recuperado de http://polired.upm.es/index.php/lacuestionuniversitaria/article/view/3401

Fundación Telefónica (2012). Universidad 2020: El papel de las TIC en el nuevo entorno socioeconómico. Recuperado de https://goo.gl/6rDA8S

García-Valcárcel, A y Martín, M. (2016). Análisis de las competencias digitales de los graduados en titulaciones de maestro. Revista Latinoamericana de Tecnología Educativa, 15(2), 155-168. Recuperado de http://dx.doi.org/10.17398/1695-288X.15.2.155

Hargittai, E. (2010). Digital Na(t)ives? Variation in Internet Skills and Uses among Members of the Net Generation”. Sociological Inquiry, 1(80), 92-113. http://dx.doi.org/10.1111/j.1475- 682X.2009.00317.x

Hipola, Pedro.et al. (2017). La carrera de Ciencias de la Documentación en la actualidad: (Debate coordinado por Manuel Blázquez). Clip de Sedic: Revista de la Sociedad Española de Documentaicón e Información Científica.75. https://clip.sedic.es/article/la-carrera-ciencias-la-documentacion-laactualidad/

Lévano, L.; Sánchez, S.; Guillén, P.; Tello, S.; Herrera, N.; Collantes, Z. (2019). Competencias digitales y educación. Propósitos y Representaciones, 7(2), 569-588. Recuperado de http://dx.doi.org/10.20511/pyr2019.v7n2.329

Moellar, S.; Joseph, A.; Lau, J; Carbo, T. (2011). Towards Media and Information Literacy Indicators. Paris: UNESCO. Recuperado de https://goo.gl/04syAg

Montes, E. (1995). El mercado de trabajo de los documentalistas en España: análisis de una muestra de ofertas de empleo, 1984-1994. Revista española de documentación científica, 18(2), 178-187. Recuperado de http://dx.doi.org/10.3989/redc.1995.v18.i2.655

Morales, C. (2012). Mapa de los estudios de información y documentación en España. Clip: boletín de Sedic, 66. Recuperado de http://www.sedic.es/p_boletinclip66_panorama_imprimir.htm

Moreiro, José. (2015). Al hilo de las noticias sobre planes de estudio y mercado de trabajo. Anuario ThinkEPI. 9 (1), 13-24. Recuperado de https://doi.org/10.3145/thinkepi.2015.02

Múnera, MT.; Jaramillo, O.; Mocada, JD (2014). Procesos de autoevaluación en la Escuela Interamericana de Biblioteconomía de la Universidad de Antioquia, en clave invetigación. Investigación bibliotecológica, 28(62), 123141. Recuperado de http://revib.unam.mx/ib/index.php/ib/issue/view/3653/showToc

OECD (2005). The definition and selection of key competencies. Executive summary. 27 May, 2005. Recuperado de http://www.oecd.org/pisa/

Oficina Regional de Educación para América Latina y el Caribe (OREALC/UNESCO Santiago) (2013). Situación Educativa de América Latina y el Caribe: Hacia la educación de calidad para todos al 2015. UNESCO. Recuperado de https://goo.gl/Z12Ysx

PAE (2019). Propuesta de Agenda Digital para España 25/07/2012. Recuperado de https://administracionelectronica.gob.es/pae_Home 
Portal de Transparencia (2015). Agenda Digital 3. Plan de impulso para la economía digital y los contenidos digitales [España]. Recuperado de https://trasnparencia.gob.es

Portal de Transparencia (2015). Agenda Digital 7. Plan de Inclusión Digital y Empleabilidad [España]. Recuperado de https://trasnparencia.gob.es

Prensky, M. (2011). Enseñar a nativos digitales. España: Madrid Ediciones MS. Recuperado de http://goo.gl/0x2awj

QAA. (2018). Subject Benchmark Statements. European Quality Assurance Agency for Higher Education. Recuperado de https://www.qaa.ac.uk/qualitycode/subject-benchmark- statements

Reinoso, JF. (2012). Aplicación de un ambiente virtual de aprendizaje orientado a la formación empresarial. Estudios gerenciales, 122(28), 105-119. Recuperado de http://dx.doi.org/10.1016/S0123- 5923(12)70196-1

Rychen, S y Salfanik, L. (2008). Definir y seleccionar las competencias fundamentales para la vida. México: Fondo de Cultura Económica.

Tejada-Artigas, C y Moreiro-González, JA. (2003). Mercado de trabajo en biblioteconomía y documentación. Estudios sobre la inserción laboral de los titulados universitarios. El profesional de la información, 12 (1), 4-9. Recuperado de http://dx.doi.org/10.1076/epri.12.1.4.19700

The Royal School of Library and Information Science (2005). European Curriculum Reflections on Library and Information Science. Copenhagen: Leif Kajberg and Leif Lørring. Recuperado de https://www.semanticscholar.org/paper/European-Curriculum-Reflectionson-Library-and- KajbergL\%C3\%B8rring/0eae21515b8a1cd508e3b11bfda5896229359e19

Universidad de Murcia (2019). Memoria verificada de grado en Información y Documentación 2010. Recuperado de https://www.um.es/web/estudios/grados/documentacion/gestiontitulacion/documentacion-titulo

Universidad de Murcia (2019). Plan de estudios y guías docentes del Grado en Información y Documentación. Recuperado de https:/www.um.es/web/estudios/grados/documentacion/plan-guias 